\title{
Antibiotic prescribing by general dental practitioners in the Greater Glasgow Health Board, Scotland
}

\author{
K. M. Roy, ${ }^{1}$ and J. Bagg, ${ }^{2}$
}

Objective To investigate antibiotic prescribing patterns by general dental practitioners (GDPs) in the Greater Glasgow Health Board Area, Scotland.

Study design A $10 \%$ sample of prescriptions were selected at random from 35, 545 prescriptions written by GDPs over a 6-month period.

Main outcome measures Absolute and relative frequencies were used to describe the different classes of antibiotics used and the variations in prescribing practice.

Results GDPs prescribed a wide range of antibiotics. Seventeen different antibiotics were prescribed with amoxycillin, metronidazole and penicillin $\mathrm{V}$ accounting for almost $90 \%$ of the prescriptions. In general the antibiotics were prescribed at the British National Formulary (BNF) recommended doses. There were, however, wide variations in the frequencies and durations of the prescriptions for all antibiotics.

Conclusions The present study provides evidence of sub-optimal prescribing of antibiotics by dentists in Scotland, with considerable variation from the recommended frequencies and doses.

$\mathrm{M}$ icrobial resistance to antibiotics is an increasingly important public health issue, prompting recent reports from high profile bodies in the UK. ${ }^{1,2}$ Inappropriate prescribing of antibiotics within the primary care setting is a major cause of drug resistance. Such misuse includes incorrect dose and duration of antibiotic therapy, inappropriate choice of antibiotic and the use of an antibiotic in unwarranted clinical situations. Recent evidence has shown that much prescribing by healthcare workers is suboptimal and it has been suggested that $75 \%$ of antibiotic use is of questionable therapeutic value. ${ }^{3}$

Although attention has been focused on medical practitioners, dentists are also prescribers, though accounting for only a small fraction of total antibiotic usage. Nonetheless, dental practice is significant for certain antimicrobials which dentists prescribe frequently. For example, dental prescribing of metronidazole accounted for $45 \%$ of all metronidazole prescriptions in the community services of the NHS in $1996 .{ }^{2}$ Prescriptions of antibiotics by the dental profession in the UK cost the General Dental Services at least $\mathfrak{E} 4.5$ million per year. ${ }^{4}$ On top of such visible sums are the potential hidden expenses caused by inappropriate blind treatment of antibiotic resistant infections. There are no data on the effect of antimicrobial resistance and treatment outcome in acute dental infections.

\footnotetext{
$1^{*}$ Research Assistant, ${ }^{2}$ Professor of Clinical Microbiology, Infection Research Group, University of Glasgow Dental School, Glasgow, Scotland

${ }^{*}$ Correspondence to: K. Roy

REFEREED PAPER

Received 24.08.99; accepted 01.02.00
}

(c) British Dental Journal 2000; 188: 674-676
General dental practitioners (GDPs) prescribe antibiotics regularly for the management of oral and dental infections. The drugs they prescribe under the NHS are restricted by the Secretary of State and listed in the Dental Practitioners' Formulary ${ }^{5}$ but definitive prescribing guidelines are not provided at present. Consequently, treatment is often empirical, guided by personal experience and knowledge. ${ }^{6}$

There has been a worrying increase in the levels of antibiotic resistance among organisms in the oral cavity across a wide genera of species. ${ }^{7,8}$ A recent study has noted the presence of beta-lactamase production in $31 \%$ of Prevotella species. ${ }^{9}$ Similarly, $54 \%$ of strains of Strep. mitis isolated from dentoalveolar aspirates in Glasgow (1993-1998) were shown to be penicillin resistant. ${ }^{10}$ There is also some evidence to suggest that penicillin resistance in Strep. pneumoniae may have been derived from viridans streptococci such as Strep. oralis ${ }^{11}$ or Strep. mitis. ${ }^{12}$

More than ten years ago, a study of antibiotic prescribing by dentists at Manchester Dental Hospital concluded that there were too many prescriptions and too few alternative surgical procedures employed. ${ }^{13}$ A similar study from Cardiff Dental School suggested that the situation had remained the same in the mid-90s, although the antibiotics of choice had changed, with metronidazole being the most common drug prescribed in the latter study. ${ }^{14}$ In general practice, the situation appears to be similar. One study, examining the management of acute dentoalveolar infections, concluded that awareness about the use of antibiotics by GDPs needs to be increased. ${ }^{15}$ More recently, a survey in Merseyside, England examined dental prescriptions issued over a 1-month period and confirmed that dentists prescribed antibiotics for inappropriately long periods, with inconsistent frequency and duration. ${ }^{16}$

In order to determine whether the prescribing habits of a cohort of Scottish dentists could be considered inappropriate or not, this study examined a sample of all antibiotic prescriptions written by GDPs in the Greater Glasgow Health Board, Scotland over a period of 6 months in 1998.

\begin{tabular}{|c|c|}
\hline Antibiotic prescribed & No. of prescriptions \\
\hline $\begin{array}{l}\text { Amoxycillin } \\
\text { Metronidazole } \\
\text { Penicillin V } \\
\text { Erythromycin } \\
\text { Cephalosporins } \\
\text { Ampicillin } \\
\text { Tetracyclines } \\
\text { Clindamycin }\end{array}$ & $\begin{array}{r}1,743 \\
788 \\
657 \\
236 \\
52 \\
33 \\
23 \\
18\end{array}$ \\
\hline Total & 3,550 \\
\hline
\end{tabular}


Table 2 Percentage of antibiotics prescribed for each dose

\begin{tabular}{|c|c|c|c|c|c|c|c|c|}
\hline \multirow[t]{2}{*}{ Dose } & \multirow[b]{2}{*}{ Amox } & \multirow[b]{2}{*}{ Metr } & \multirow[b]{2}{*}{ Pen ${ }^{1}$} & \multicolumn{2}{|c|}{ Antibiotic (\%) } & \multirow[b]{2}{*}{ Amp } & \multirow[b]{2}{*}{ Tetr } & \multirow[b]{2}{*}{ Clind $^{2}$} \\
\hline & & & & Eryth & Cephal & & & \\
\hline $75 \mathrm{mg}$ & & & & & & & & 6 \\
\hline $100 \mathrm{mg}$ & & & & & & & 60.9 & \\
\hline $125 \mathrm{mg}$ & 10.6 & & 12.2 & 8.5 & 3.8 & & & \\
\hline $200 \mathrm{mg}$ & & 88.9 & & & & & & 94 \\
\hline $250 \mathrm{mg}$ & 58.7 & & 87.8 & 86 & 63.5 & 78.8 & 39.1 & \\
\hline $400 \mathrm{mg}$ & & 11.1 & & & & & & \\
\hline $500 \mathrm{mg}$ & 21.2 & & & 5.5 & 32.7 & 21.2 & & \\
\hline $750 \mathrm{mg}$ & 0.2 & & & & & & & \\
\hline $3 \mathrm{~g}$ & 9.3 & & & & & & & \\
\hline
\end{tabular}

The recommended Dental Practitioners' Formulary (DPF) doses highlighted in bold.

${ }^{1}$ Penicillin recommended dose - 125-750 mg

${ }^{2}$ Clindamycin recommended dose $-150-300 \mathrm{mg}$

\section{Methods}

Within Scotland, prescriptions written by general practitioners (both medical and dental) are collated by the Information and Statistics Division (ISD Scotland), Primary Care Information Unit, Edinburgh, providing availability of a range of data for the analysis of trends in general practice prescribing.

Data about prescribing by general dental practitioners (GDPs) in the Greater Glasgow Health Board (GGHB) over a 6-month period (May 1998-Oct. 1998) were obtained from ISD. Within Scotland, the GGHB has the largest single proportion of dentists practising within its boundaries, accounting for a quarter of all Scottish dentists.

The name of the antibiotic (generic or proprietary), the formulation, the strength (dose) and the quantity of antibiotic dispensed were supplied. The information was provided in an anonymous format. From a total of 35,545 prescriptions, a $10 \%$ sample was selected at random by computer (Minitab 10.5). The duration and frequency of a course of antibiotics was calculated from the strength of antibiotic prescribed and the quantity dispensed using the standard provided by the British National Formulary (BNF). ${ }^{5}$ For example, the recommended frequency for amoxycillin is $250 \mathrm{mg}$ three times daily, therefore, if $15 \times 250 \mathrm{mg}$ tablets were prescribed this would equate to a 5-day course. Data analysis was carried out using Minitab 10.5. Absolute and relative frequencies were measured to describe the different classes of antibiotics used and to examine the variations in prescribing practice.

\section{Results}

A total of 17 different antibiotics were prescribed. This included generic (12) and proprietary (5) named drugs. The antibiotics prescribed were grouped by antibiotic type with the exception of the penicillins and the macrolides. Table 1 shows the antibiotics prescribed in the sample. Amoxycillin, metronidazole and penicillin $\mathrm{V}$ accounted for almost $90 \%$ of the antibiotics prescribed.

With the exception of the tetracyclines, the antibiotics were prescribed at the Dental Practitioners' Formulary (DPF) recommended dose(s) (Table 2). There were, however, wide variations in the frequency and duration of the prescriptions for all the antibiotics.

Amoxycillin was prescribed in three formulations: capsule (78\%), oral solution (12\%) and oral powder (10\%). In capsule and solution formulas, amoxycillin was prescribed on average for 5 days ( $\mathrm{min}$ 2 days; max 20 days). Although the majority (73\%) prescribed amoxycillin in the capsule formulation at the correct dose, only $42 \%$ used the correct frequency and duration (Table 3). Only one of 213 prescriptions of amoxycillin oral solution was given at the correct frequency and duration (three times daily for 5 days), the majority of prescriptions being a 5-day course, four times daily. In contrast, amoxycillin oral powder was prescribed correctly in $90 \%$ of cases.
Metronidazole was the second most frequent antibiotic prescribed. Although the majority of practitioners prescribed the correct dose, there was some anomalous prescribing encountered with regard to frequency and duration (Table 4).

Penicillin V, the third most popular antibiotic, accounted for a fifth of all prescriptions written during the period studied. Although a range of doses are acceptable depending on age of the patient and severity of infection, a frequency of four times daily is recommended by the BNF. This advice was followed in more than $90 \%$ of prescriptions. The majority provided a 5 -day course (min 2 days, max 20 days), though a large number (34\%) prescribed a course for 7 days or longer (Table 5).

Erythromycin, the cephalosporins, ampicillin, tetracyclines and clindamycin accounted for the remaining $10 \%$ of prescriptions written over the 6-month period. Wide variations in doses, frequency and duration were also observed in this group with a number of anomalous prescriptions being noted. For example, one prescription provided a course of tetracycline (four times daily, $250 \mathrm{mg}$ ) for 90 days.

Table 3 Frequency and duration of amoxycillin capsules

\begin{tabular}{ccccc}
\hline $\begin{array}{c}\text { Duration } \\
\text { (days) }\end{array}$ & \multicolumn{4}{c}{$\begin{array}{c}\text { No. of prescriptions } \\
\text { Three times daily }\end{array}$} \\
\cline { 4 - 5 } & $250 \mathrm{mg}$ & $500 \mathrm{mg}$ & $250 \mathrm{mg}$ & $500 \mathrm{mg}$ \\
\hline 2 & 0 & 1 & 0 & 0 \\
3 & 1 & 1 & 0 & 0 \\
4 & 6 & 6 & 3 & 0 \\
5 & 418 & 172 & 194 & 66 \\
6 & 7 & 1 & 37 & 7 \\
7 & 167 & 74 & 121 & 16 \\
9 & 5 & 1 & 1 & 0 \\
10 & 22 & 21 & 5 & 1 \\
12 & 0 & 0 & 2 & 0 \\
14 & 7 & 0 & 0 & 0 \\
20 & 1 & 3 & 0 & 0
\end{tabular}

Table 4 Frequency and duration of metronidazole treatment

\begin{tabular}{ccccc}
\hline $\begin{array}{c}\text { Duration } \\
\text { (days) }\end{array}$ & \multicolumn{5}{c}{$\begin{array}{c}\text { No of prescriptions } \\
\text { Three times daily }\end{array}$} & \begin{tabular}{c} 
Four times daily \\
\hline
\end{tabular} & $200 \mathrm{mg}$ & $400 \mathrm{mg}$ & $200 \mathrm{mg}$ & $400 \mathrm{mg}$ \\
\hline 3 & 117 & 6 & 0 & 0 \\
4 & 20 & 3 & 3 & 0 \\
5 & 401 & 55 & 36 & 2 \\
6 & 6 & 0 & 4 & 0 \\
7 & 95 & 19 & 2 & 1 \\
10 & 15 & 0 & 0 & 0 \\
14 & 0 & 1 & 0 & 0 \\
15 & 1 & 1 & 0 & 0 \\
\hline
\end{tabular}


Table 5 Frequency and duration of penicillin treatment

\begin{tabular}{cccc}
\hline $\begin{array}{c}\text { Duration } \\
\text { (days) }\end{array}$ & \multicolumn{3}{c}{$\begin{array}{c}\text { No of prescriptions } \\
\text { Four times daily }\end{array}$} \\
\cline { 2 - 3 } & $250 \mathrm{mg}$ & $125 \mathrm{mg}$ & $250 \mathrm{mg}$ \\
\hline 2 & 0 & & \\
3 & 2 & 0 & 1 \\
4 & 1 & 0 & 0 \\
5 & 1 & 0 & 0 \\
6 & 0 & 79 & 322 \\
7 & 2 & 0 & 29 \\
9 & 13 & 0 & 98 \\
10 & 25 & 0 & 1 \\
14 & 1 & 0 & 59 \\
20 & 8 & 0 & 13 \\
& & 0 & 1 \\
\hline
\end{tabular}

\section{Discussion}

The dental profession should be aware that antibiotic resistance is an emerging problem created largely by overuse and inappropriate use of antibiotics. The present study shows evidence of poor prescribing of antibiotics by dentists in Scotland. The data reveal dentists prescribing a wide spectrum of antibiotics and, in agreement with previous studies, ${ }^{13-16}$ there was considerable variation from the recommended frequencies and doses. In our investigation, more than half of all the prescriptions written were for a course of antibiotics of 5 days or more, contrary to current views on the merits of shorter courses. ${ }^{17-19}$

The dose and the duration of therapy are key factors in modulating the selection pressure for antibiotic resistance. It is essential that antibiotics be prescribed at the correct frequency so that the minimum inhibitory concentration is exceeded and the infecting bacteria are killed rather than merely inhibited. Use of doses that are too small or treatments that are too long have recently been shown to increase the risk of selecting resistant strains. ${ }^{20}$ Unfortunately, the optimal duration of antibiotic therapy for many dental infections has never been defined by randomised controlled trials. Currently, guidelines are based on expert opinion which is considered to be the lowest level of evidence. There is an urgent need for randomised controlled trials with objective outcome measures to provide a scientific basis for recommendations on best practice. Until such data exist, the antimicrobial pharmacokinetics of vigorous dosage and short duration should be applied.

Lack of guidelines may impede the selection of the most effective antimicrobial therapy, though the variability of antibiotic prescribing by dentists cannot be attributed solely to this deficiency. In addition, factors such as education, experience, patient expectation and economics are important. As a result, a co-ordinated effort between dentists, dental educators, patients and regulators is required to improve the use of antibiotics in practice. ${ }^{21}$

There is no doubt that antibiotic use must be rational and moderate to reduce the development of cross-resistance and needless patient exposure. Such prescribing is an important objective on both clinical and financial grounds. However, this presupposes knowledge of the infecting pathogenic microorganism. The mouth is the habitat for hundreds of microbial species, many of which are implicated in dental infections, often in combination. ${ }^{22}$ Thus it is advisable that microbiological sampling should be carried out, particularly in severe infections. ${ }^{5}$ In general practice, however, therapy is usually initiated on an empirical basis and little use is made of diagnostic microbiology services. ${ }^{23}$ Improving the availability of such services and provision of training in their use, should be an integral part of our response to poor antibiotic prescribing. In addition, the taught principles for treating dental and oral infections suggest that an antibiotic should only be used to support, and not to replace, conventional surgical methods. Many infections can be treated effectively by surgical means alone, with no recourse to antimicrobial drugs whatsoever, a fact which should be reinforced to dental surgeons as part of the overall strategy to reduce antimicrobial prescribing in dentistry.

The Information and Statistics Division (ISD Scotland), Primary Care Information Unit, Edinburgh, are thanked for their support and the provision of the antibiotic prescriptions data.

1 Select Committee on Science and Technology. Resistance to antibiotics and other antimicrobial agents. London: HMSO, 1998.

2 Standing Medical Advisory Committee, Sub-Group on Antimicrobial Resistance. The path of least resistance. London: Stationery Office, 1998.

3 Wise R, Hart T, Cars O et al. Antimicrobial resistance. Br Med J 1998; 317: 609-610.

4 Dental Practice Board. Digest of Statistics, 1996/97, Part 1: Detailed analysis of GDS treatment items. Eastbourne, 1998.

5 British Dental Association; British Medical Association; Royal Pharmaceutical Society of Great Britain. British National Formulary, editor. Dental Practitioners' Formulary (1998-2000). 36 ed. London: British Medical Association and the Royal Pharmaceutical Society of Great Britain, 1998.

6 Palmer N, Ireland R, Palmer S. Antibiotic prescribing patterns of a group of general dental practitioners: results of a pilot study. Primary Dental Care 1998; 5: 137-141.

7 Lewis M A O, Pankhurst C L, Douglas C I et al. Prevalence of penicillinresistant bacteria in acute suppurative oral infection. J Antimicrob Chemother 1995; 36: 883.

8 Teng L-J, Hsueh P-R, Chen Y-C, Ho S-W, Luh K-T. Antimicrobial susceptibility of viridans group streptococci in Taiwan with an emphasis on the high rates of resistance to penicillin and macrolides in Streptococcus oralis. J Antimicrob Chemother 1998; 41: 621-627.

9 Matto J, Asinkainen S, Vaisanen M-L et al. Beta-lactamase production in Prevotella intermedia, Prevotella nigrescens, and Prevotella pallens genotypes and in vitro susceptibilities to selected antimicrobial agents. Antimicrob Agents Chemother 1999; 43: 2383-2388.

10 Smith A, Dickson E, Roy K et al. The epidemiology of penicillin and erythromycin resistance in oral streptococcal isolates from acute dentoalveolar infections in Glasgow 1993-1998. SCIEH Weekly Report 1999; 33: 144-145.

11 Coffey T J, Dowson C G, Daniels M, Spratt B G. Horizontal spread of an altered penicillin-binding protein $2 \mathrm{~b}$ gene between streptococcuspneumoniae and streptococcus-oralis. FEMS Microbiol Lett 1993; 110: 335339.

12 Dowson C G, Coffey T J, Kell C, Whiley R A. Evolution of penicillin resistance in streptococcus-pneumoniae - the role of streptococcus-mitis in the formation of a low-affinity pbp2b in streptococcus-pneumoniae. Mol Microbiol 1993; 9: 635-643.

13 Barker G R, Qualtrough A J E. An investigation into antibiotic prescribing at a dental hospital. Br Dent J 1986; 162: 303-307.

14 Thomas D W, Satterthwaite J, Absi E G, Shepherd J P. Antibiotic prescription for acute dental conditions in the primary-care setting. $\mathrm{Br}$ Dent J 1996; 181: 401-404.

15 Muthukrishnan A, Walters H, Douglas P S. An audit of antibiotic prescribing in general practitioners in the initial management of acute dental infection. Dent Update 1996; 23: 316-318.

16 Palmer N, Martin M. An investigation of antibiotic prescribing by general dental practitioners: a pilot study. Primary Dental Care 1998; 5: 11-14.

17 Slots J. Systematic antibiotics in periodontics. J Perio 1996; 67: 831-838.

18 Martin M V, Long L P, Hill J B, Hardy P. Acute dentoalveolar infections: an investigation of the duration of antibiotic therapy. Br Dent J 1997; 183: 135-137.

19 Lewis M A O, McGowan D A, MacFarlane T W. Short course high dosage amoxycillin. The treatment of acute dentoalveolar abscess. Br Dent J 1986; 161: 299.

20 Guillemot D, Carbon C, VauzelleKervroedan F et al. Inappropriateness and variability of antibiotic prescription among French office-based physicians. JClin Epidemiol 1998; 51: 61-68.

21 Turnidge J. What can be done about resistance to antibiotics? Br Med J 1998; 317: 645-647.

22 Lewis M A O, MacFarlane T W, McGowan D A. A microbiological and clinical review of the acute dentoalveolar abscess. Br J Oral Maxillofac Surg 1990; 28: 359-366.

23 Roy K M, Smith A, Sanderson J et al. Barriers to the use of a diagnostic oral microbiology laboratory by General Dental Practitioners. Br Dent J 1999; 186: $345-347$ 